\title{
APPLICATION OF THE BOUNDARY \\ ELEMENT METHOD FOR THE CALCULATION OF THE ROD CARRIER SYSTEM OF CRANES
}

\author{
Orobey V. F., Nemchuk O. O., Lymarenko O. M.
}

\section{INTRODUCTION}

Mechanical systems with non-conservative forces are widely used in the life of modern society. Systems with internal sources of energy can be attributed to such systems: these are rockets, planes, space stations, oil derricks and platforms, turbines, internal combustion engines, metal-cutting machines, various cranes, high-pressure pipelines etc.

The conservative problems of the stability can be solved only with a static method while the non-conservative tasks can be served with the help of dynamic method which is presented only in the works of professor A. Dashchenko ${ }^{1}$. The main element of BEM for the dynamic method is solution of Cauchy problem for the bar lateral oscillations considering the longitudinal force. The given solution is convenient to be introduced in the matrix form.

\begin{tabular}{|c|c|c|c|c|c|c|c|c|}
\hline $\operatorname{EI} U(x)$ & \multirow{4}{*}{$=$} & $\mathrm{A}_{11}$ & $\mathrm{~A}_{12}$ & $-A_{13}$ & $-A_{14}$ & E I $V(0)$ & \multirow{2}{*}{\multicolumn{2}{|c|}{\begin{tabular}{ll}
\cline { 2 - 3 } & $\mathrm{A}_{14}(\mathrm{x}-\xi)$ \\
\cline { 2 - 2 } & $\mathrm{A}_{13}(\mathrm{x}-\xi)$
\end{tabular}}} \\
\hline $\mathrm{E} I \varphi(\mathrm{x})$ & & $\mathrm{A}_{21}$ & $\mathrm{~A}_{11}$ & $-A_{23}$ & $-A_{13}$ & $\mathrm{E} I \varphi(0)$ & & \\
\hline $\mathrm{M}(\mathrm{x})$ & & $-\mathrm{A}_{31}$ & $-\mathrm{A}_{21}$ & $\mathrm{~A}_{33}$ & $\mathrm{~A}_{23}$ & $\mathrm{M}(0)$ & 0 & $-\mathrm{A}_{23}(\mathrm{x}-\xi)$ \\
\hline $\mathrm{Q}(\mathrm{x})$ & & $-\mathrm{A}_{41}$ & $-A_{31}$ & $\mathrm{~A}_{43}$ & $\mathrm{~A}_{33}$ & $\mathrm{Q}(0)$ & 0 & $-\mathrm{A}_{33}(\mathrm{x}-\xi)$ \\
\hline
\end{tabular}

where fundamental orthonormalized functions have the following view:

$$
\begin{gathered}
A_{11}=\frac{\beta^{2} \operatorname{ch} \alpha x+\alpha^{2} \sin \beta x}{\alpha^{2}+\beta^{2}} ; A_{12}=\frac{\beta^{3} \operatorname{sh} \alpha x+\alpha^{3} \sin \beta x}{\alpha^{3} \beta+\alpha \beta^{3}} ; A_{13}=\frac{\operatorname{ch} \alpha x-\cos \beta x}{\alpha^{2}+\beta^{2}} ; \\
A_{14}=\frac{\beta^{2} \operatorname{sh} \alpha x-\alpha \sin \beta x}{\alpha^{3} \beta+\alpha \beta^{3}} ; A_{21}=\alpha^{2} \beta^{2} A_{14} ; \\
A_{23}=\frac{\alpha \operatorname{shax}+\beta \sin \beta x}{\alpha^{2}+\beta^{2}} ; A_{31}=\alpha^{2} \beta^{2} A_{13}
\end{gathered}
$$

${ }^{1}$ Orobej V. F. Metod granichnyh jelementov v zadachah ustojchivosti ploskoj formy izgiba balok prjamougol'nogo sechenija [Method of boundary ele-ment in problems of stability of plane bending beams of rectangular cross section]. Zbirnik naukovih prac' Odes'koi deržavnoi akademii tehničnogo regu-lûvannâ ta âkostì. Odesa, 2015. № 2 (7). S. 47-54. 


$$
\begin{aligned}
A_{33} & =\frac{\alpha^{2} \operatorname{ch} \alpha x+\beta^{2} \cos \beta x}{\alpha^{2}+\beta^{2}} ; \quad A_{41}=\alpha^{2} \beta^{2} A_{23} ; \quad A_{43}=\frac{\alpha^{3} \operatorname{sh} \alpha x-\beta^{3} \sin \beta x}{\alpha^{2}+\beta^{2}} \\
\alpha & =\sqrt{-\frac{F}{2 E I}+\sqrt{\left(\frac{F}{2 E I}\right)^{2}+\frac{\omega^{2} m}{E I}}} ; \beta=\sqrt{\frac{F}{2 E I}+\sqrt{\left(\frac{F}{2 E I}\right)^{2}+\frac{\omega^{2} m}{E I}}}
\end{aligned}
$$

Expressions (2) proceed to the famous functions of A.N. Krylov ${ }^{2}$ at $F=0$.

In contrast to the static method, the critical force in the dynamic method is defined in the point where two neighboring frequencies of free oscillations become equal (merge). Therefore, the initial data of compressing force is input in the program and frequencies (at least two) of free oscillations from the BEM frequency equation are defined,

$$
\left|A_{*}(F, \omega)\right|=0
$$

where $A_{*}(F, \omega)$ - is the frequency matrix of the bar structures built according to the BEM algorithm. Then the value of the compressing force is increased and the frequency change is backtraced. The process continues until two neighboring frequencies become equal with the certain precision. At the same time, the value of the compressing force will be critical, and the whole process of its identification is comfortable to be presented in the form of diagrams.

The problems of stability in the Euler formulation, when the beam dimensions and the compressive force change, are reduced to boundary problems for ordinary differential equations with variable coefficients

$$
\frac{d^{2}}{d x^{2}}\left[E I(x) \frac{d^{2} \vartheta(x)}{d x^{2}}\right]+\frac{d}{d x}\left[N(x) \frac{d \vartheta(x)}{d x}\right]=0,
$$

where $E I(x)$ is the function of flexural (minimum) rigidity, $\mathrm{kNm}^{2}$;

$\vartheta(x)$ is transverse deflection, $\mathrm{m}$;

$N(x)$ is the function of compressive force in the beam section, $\mathrm{kN}$.

The analytical solution of even such a relatively simple equation causes serious mathematical difficulties. In this case, it is necessary to apply the numerical methods, for example FEM. This raises questions about the accuracy and reliability of the results. Therefore, the problem of the development of new approaches to solving this and similar tasks remains relevant.

${ }^{2}$ Orobej V. F. Metod granichnyh jelementov v zadachah rascheta mashinostroitel'nyh konstrukcij [The method of boundary elements in the problems of calculating engineering structures]. Odessa : “Aprel”, 2016. 761 s. 
Currently, the most developed numerical method is the finite element method (FEM). The search for alternative approaches led to the emergence of a new method, and more precisely, methods of boundary elements (BEM). Here, not the entire region under consideration is subjected to discretization, as in the finite element method, but only its boundary. In the field of structural mechanics, a significant number of works are devoted to this direction. However, many problems remain unresolved.

\section{ANALYSIS OF RECENT PUBLICATIONS AND PURPOSE OF RESEARCH}

Literature analysis on solution of non-conservative problems of steadiness shows, that behavior of complex bar systems such as continuous beams and frames. Therefore, let us show BEM algorithm ideally suits for identical problem-solving models with any structure of elastic system. A random set of bars can be a model of the object. Each of those bars can have an infinite number of degrees of freedom. Moreover, displacement, rotation inertia, inside and inner friction, optional laws of mass and rigidity change, longitudinal forces and other factors can be present. Non-conservativeness of compressing forces in BEM is considered with a proper formulation of boundary conditions for an elastic system. Boundary conditions are non-linear for a separate bar and are linearized considering a smallness of proper dislocation, i.e. the equalities are true

$$
\sin \psi=\operatorname{tg} \psi=\psi ; \cos \psi=1,
$$

where $\psi$-is an angle between the force of $F$ and a normal to the bar axis (Fig. 1).

Boundary conditions for the force of $F$ in Fig.1, $a$ are quite simple:

$$
\psi=\frac{\pi}{2} ; E I v(l) \neq 0 ; E I \varphi(l) \neq 0 ; \quad M(l)=0 ; Q(l)=0
$$

In boundary section of the beam for the force of $F$ in Fig.1, $b$ the bending moment and shear arise there.

$$
\psi=\frac{\pi}{2}-\varphi(l) ; E I v(l) \neq 0 ; E I \varphi(l) \neq 0 ; \quad M(l)=F v(l) ; Q(l)=F \sin \varphi(l)
$$

If non-conservative pressure forces are applied to assemblies of continuous beams and frames, then their behavior should be taken into account with the boundary conditions of the rods that are a part of this assembly. In this paper, we consider the stability problems of bar structures on the application of force in Fig. 1. 


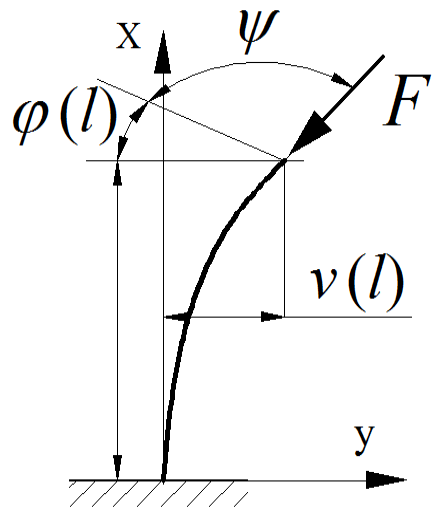

a)

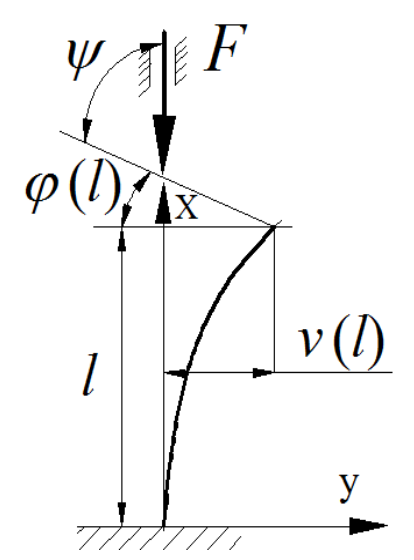

b)

Fig. 1. Alternatives of behavior for the compressing non-conservative forces:

a) following up the rotation angle of the beam section;

b) the force of $F$ has a fixed line of action

The solution of boundary problems for differential equations with variable coefficients attracts researchers by its complexity and a wide practical application. The numerical-analytical version of boundary element method (BEM) that was developed in the works of prof. Orobey V. F. ${ }^{3}$ can be successfully applied to solving differential equations with variable coefficients. However, in these works, rods, in which the section change was performed only in one direction, were considered. It's not exactly the general case. At the same time, in the scientific literature mathematical approaches to reflect changes in the dimensions of section in all directions (for example, a cone) are presented. In this regard, we will present the opportunities of BEM for such cases.

The aim of this work is to solve new non-conservative problems with continuous beams and plate frames and to study the behavior of these systems when using increasing non-conservative compression forces.

The study also conducts a numerical-analytical version of the boundary element method for solving problems of beam stability in the form of a truncated cone.

\section{Non-conservative problems of the stability of rod structures}

Continuous beam (Figure 2).

According to the BEM algorithm, it is divided into separate bars, assemblies are numerated and the start and end of each bar are marked with arrows. Then the matrices of initial and finite beam parameters are formed. These matrices consider the end conditions, boundary conditions and a connection between the boundary elements in assemblies.

${ }^{3}$ Gnedenko B. V., Belyaev Yu. K, Solovev A. D. Matematicheskie metodyi v teorii nadezhnosti. Moskva : Nauka, 1965. S. 373-375. 


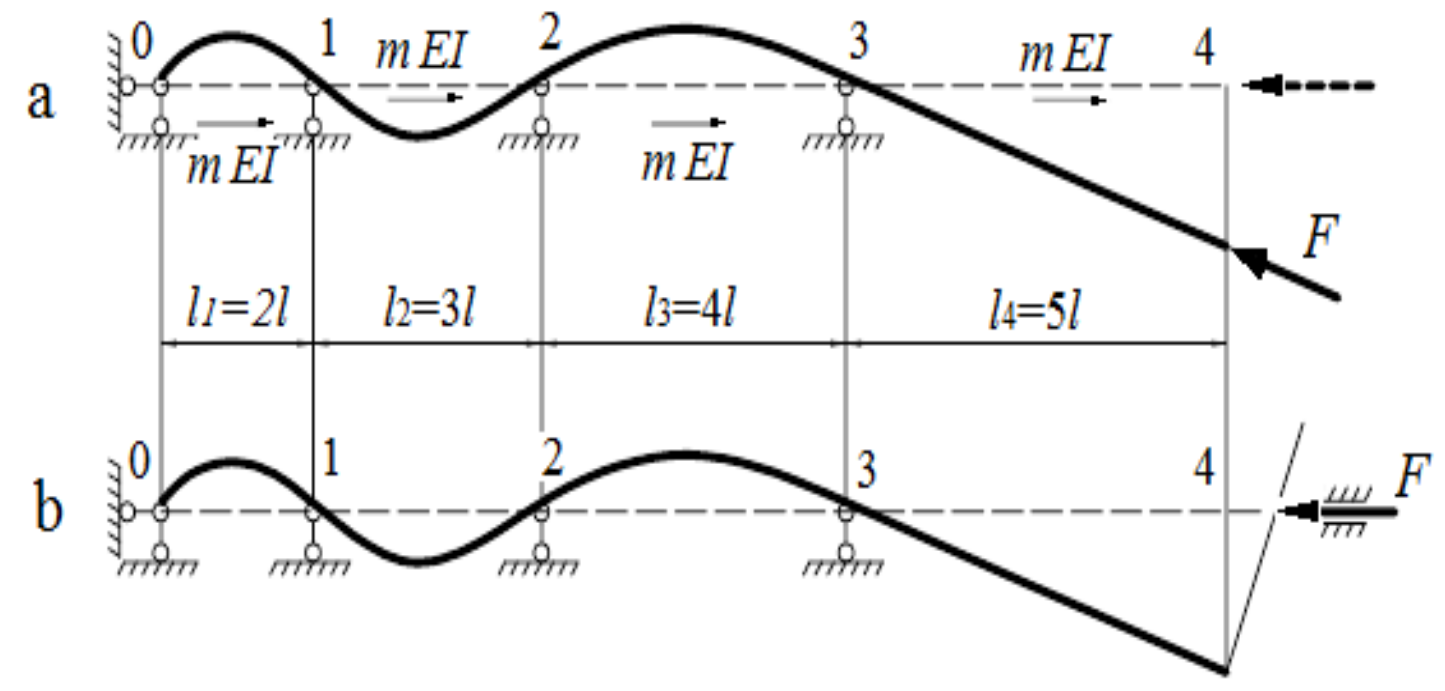

Fig. 2. Continuous beam loaded with non-conservative forces

Load non-conservativeness in Fig. 2, $a$ is shown in Matrix $Y$ in the rows from 13 to 16.

If we transfer all parameters from $Y$ to matrix $X_{*}$, we will receive matrix $A_{*}(F, \omega)$ of equation (3) for the given beam

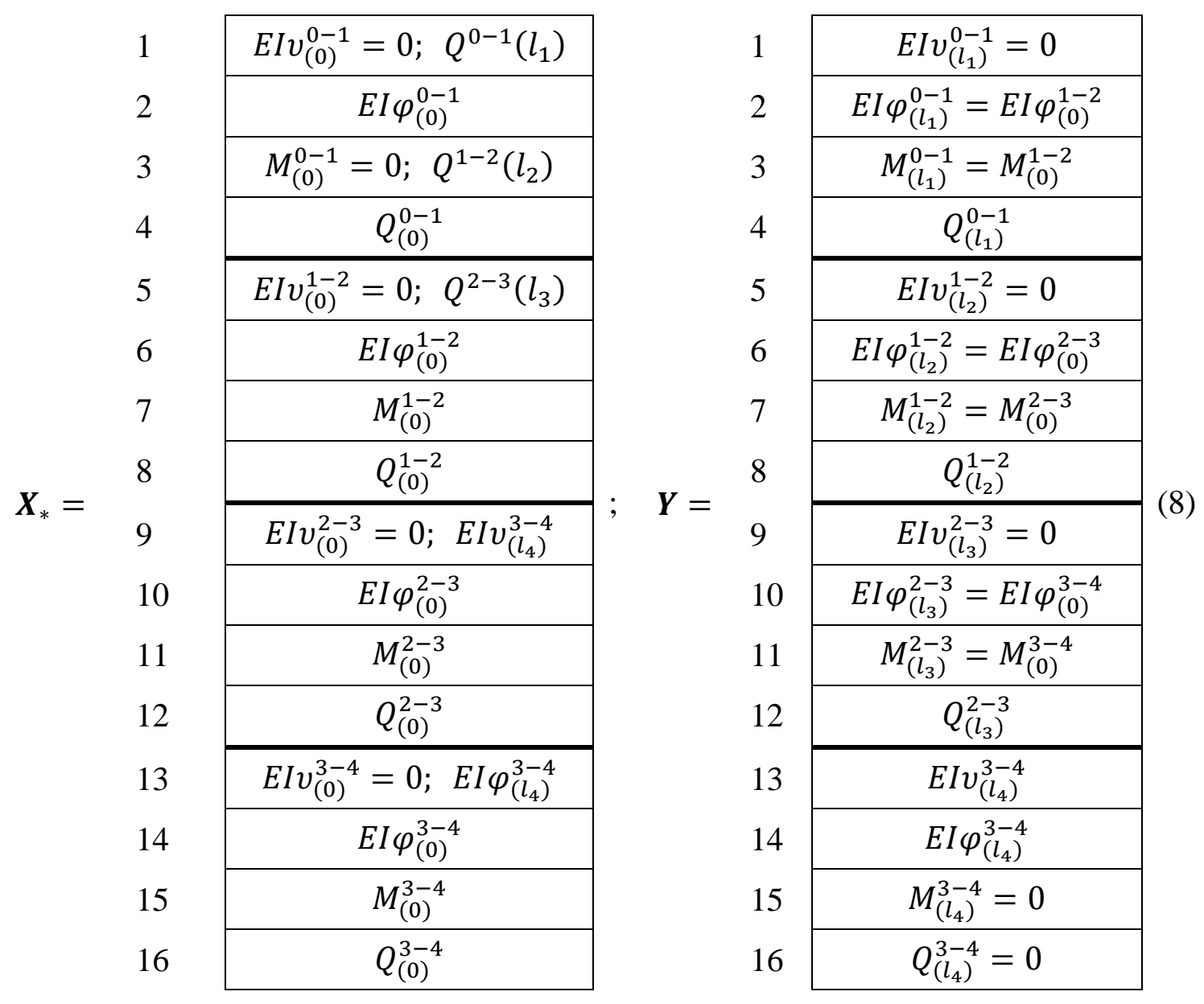




\begin{tabular}{|c|c|c|c|c|c|c|c|c|c|c|c|c|c|c|c|c|}
\hline & 1 & 2 & 3 & 4 & 5 & 6 & 7 & 8 & 9 & 10 & 11 & 12 & 13 & 14 & 15 & 16 \\
\hline 1 & & $\mathrm{~A}_{12}$ & & $-\mathrm{A}_{14}$ & & & & & & & & & & & & \\
\hline 2 & & $\mathrm{~A}_{11}$ & & $-\mathrm{A}_{13}$ & & -1 & & & & & & & & & & \\
\hline 3 & & $-\mathrm{A}_{21}$ & & $\mathrm{~A}_{23}$ & & & -1 & & & & & & & & & \\
\hline 4 & -1 & $-\mathrm{A}_{31}$ & & $A_{33}$ & & & & & & & & & & & & \\
\hline 5 & & & & & & $\mathrm{~A}_{12}$ & $-A_{13}$ & $-\mathrm{A}_{14}$ & & & & & & & & \\
\hline 6 & & & & & & $\mathrm{~A}_{11}$ & $-\mathrm{A}_{23}$ & $-\mathrm{A}_{13}$ & & -1 & & & & & & \\
\hline 7 & & & & & & $-A_{21}$ & $\mathrm{~A}_{33}$ & $\mathrm{~A}_{23}$ & & & -1 & & & & & \\
\hline$A_{*}=8$ & & & -1 & & & $-A_{31}$ & $\mathrm{~A}_{43}$ & $\mathrm{~A}_{33}$ & & & & & & & & \\
\hline 9 & & & & & & & & & & $\mathrm{~A}_{12}$ & $-\mathrm{A}_{13}$ & $-\mathrm{A}_{14}$ & & & & \\
\hline 10 & & & & & & & & & & $\mathrm{~A}_{11}$ & $-\mathrm{A}_{23}$ & $-\mathrm{A}_{13}$ & & -1 & & \\
\hline 11 & & & & & & & & & & $-\mathrm{A}_{21}$ & $\mathrm{~A}_{33}$ & $\mathrm{~A}_{23}$ & & & -1 & \\
\hline 12 & & & & & -1 & & & & & $-A_{31}$ & $\mathrm{~A}_{43}$ & $\mathrm{~A}_{33}$ & & & & \\
\hline 13 & & & & & & & & & -1 & & & & & $\mathrm{~A}_{12}$ & $-\mathrm{A}_{13}$ & $-\mathrm{A}_{14}$ \\
\hline 14 & & & & & & & & & & & & & -1 & $\mathrm{~A}_{11}$ & $-\mathrm{A}_{23}$ & $-\mathrm{A}_{13}$ \\
\hline 15 & & & & & & & & & & & & & & $-\mathrm{A}_{21}$ & $\mathrm{~A}_{33}$ & $\mathrm{~A}_{23}$ \\
\hline 16 & & & & & & & & & & & & & & $-A_{31}$ & $\mathrm{~A}_{43}$ & $\mathrm{~A}_{33}$ \\
\hline
\end{tabular}

For the case of applying force of $F$ according to Fig. 2, 8 , the next elements will be added to the matrix

$$
A_{*}(15,9)=-\frac{F}{E I} ; A_{*}(16,13)=-\frac{F}{E I} .
$$

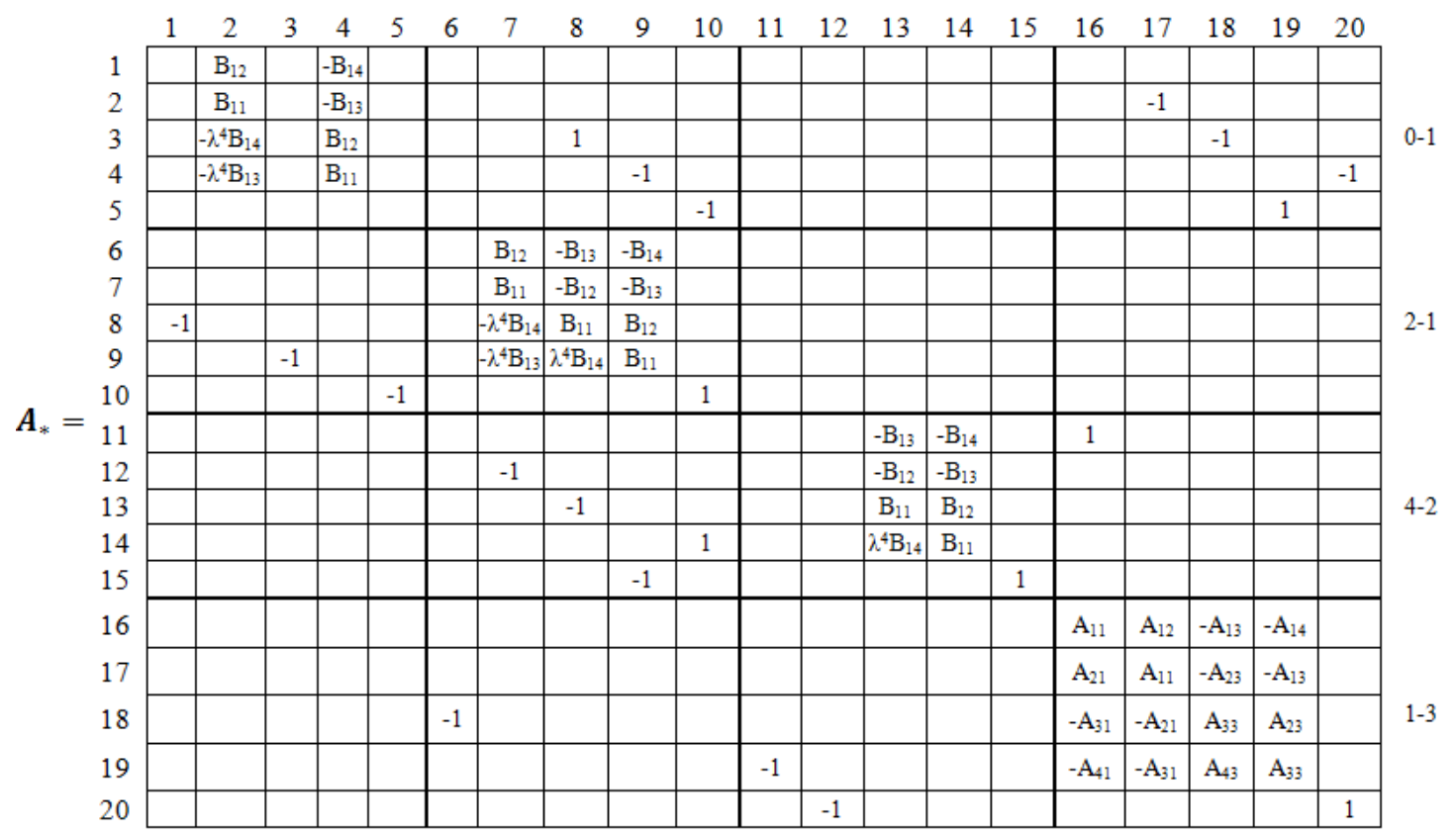

Let us review a plane frame, which studs 4 times longer than cross-bars with the same masses of $m$ and rigidity of $E I$ (fig.3). Similarly, when building matrices with initial and finite data and considering boundary data and frame 
topology, we will come to a dynamic stability matrix (10) for the frame in Fig.4, $a$. Calculation of inertia force of linear movable bars $0-1$ and 1-2 leads to the increase of the bars 1-3 and 4-2 distributed mass, i.e. $m_{*}^{1-3}$ and $m_{*}^{4-2}$.

Here we should use the functions of A.N. Krylov from the bars that are free from compressing forces

$$
\lambda=\sqrt[4]{\frac{\omega^{2} m}{E I}} ; \quad B_{11}=\frac{\operatorname{ch} \lambda x+\cos \lambda x}{2} ; \quad B_{12}=\frac{\operatorname{sh} \lambda x+\sin \lambda x}{2 \lambda} ;
$$

$$
B_{13}=\frac{\operatorname{ch} \lambda x-\cos \lambda x}{2 \lambda^{2}} ; B_{14}=\frac{\operatorname{sh} \lambda x-\sin \lambda x}{2 \lambda^{3}} ;
$$

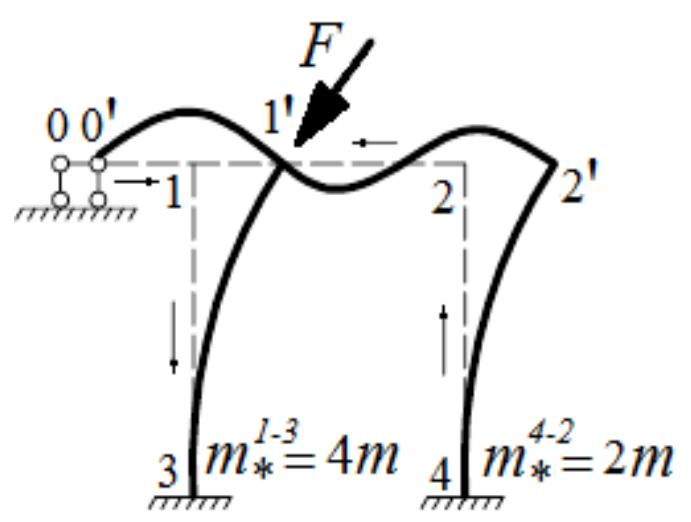

a)

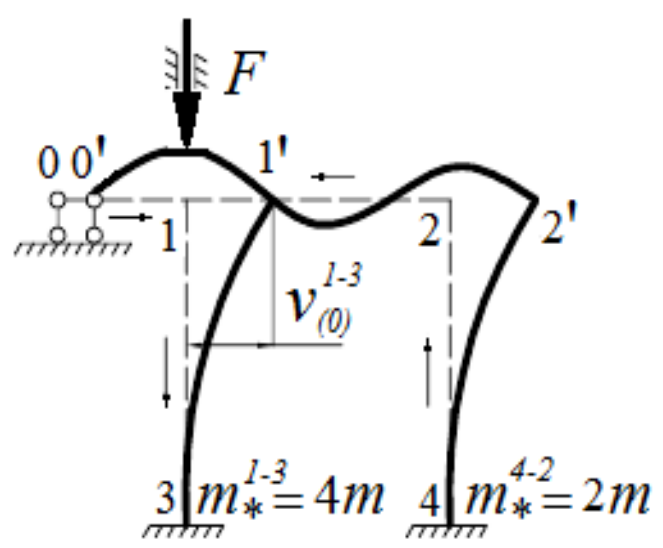

b)

Fig. 3. Plane frame: a) force of $F$ follows up the assembly rotation angle 1;

b) force of $\boldsymbol{F}$ has a fixed action line

As in the case with continuous beam, force of $F$ consideration in accordance with Fig. 3, $в$ leads to extension of elements:

$$
A_{*}(3,16)=-\frac{F}{E I} ; A_{*}(5,17)=-\frac{F}{E I} .
$$

Diagrams representing the changes in frequencies of beam free oscillations during force of $F$ increase are provided in Fig. 4.

The calculations are made in the MATLAB environment at $m=E I=$ $=l=1[4]$. From the diagrams in Fig. 4 it follows that two types of compressing forces lead to the same behaviour of continuous beam. First ensues buckling mode due to non-conservative forces (flatter or divergence) and then, if the beam is not destroyed, comes Euler's buckling mode. Critical nonconservative forces are $0,65 / 0,06468=10$ times higher than the first critical force of beam compared to Gallilei's "dead" force. 


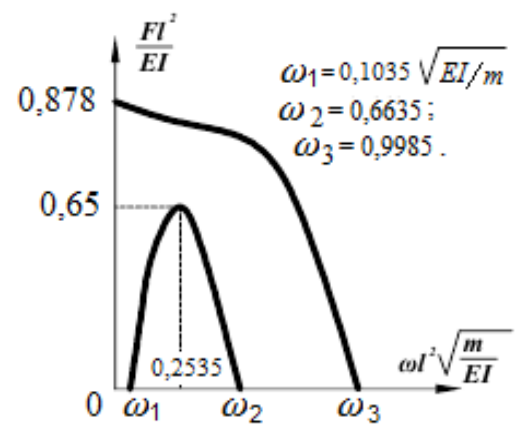

a)

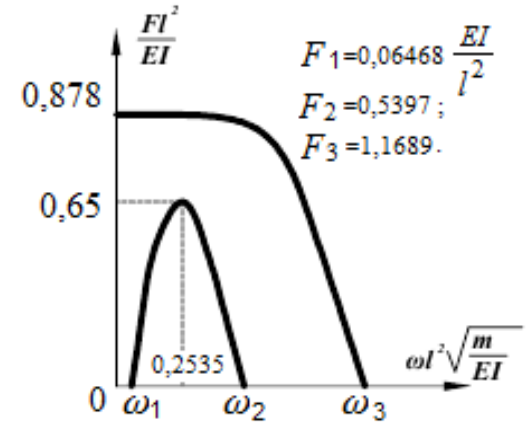

b)

Fig. 4. Dependencies of the beam oscillation frequency from compressing forces: a) - force follows the slope of the elastic curve; b) force has a fixed line of action

The relationships between compressing forces and frequencies of free oscillations are provided in Fig. 5 (the calculations are made in the MATLAB environment

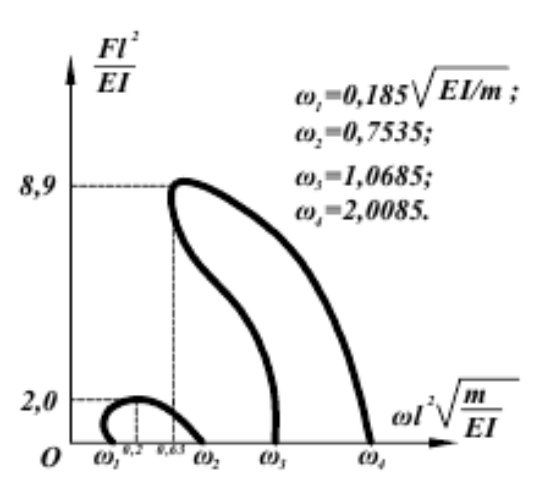

a)

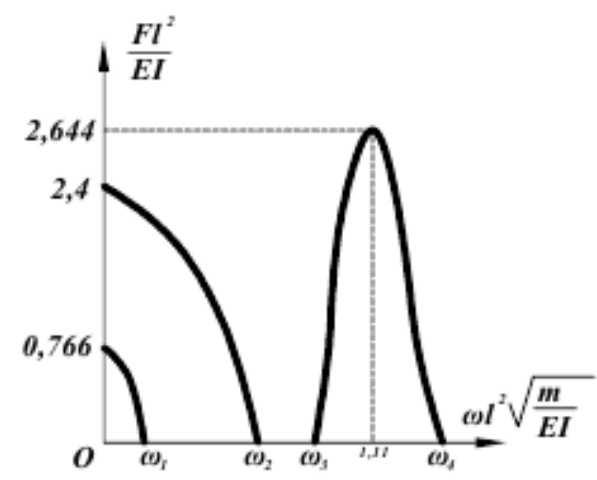

b)

Fig. 5. Dependencies of the frame oscillation frequency from compressing forces:

a) force follows up the assembly rotation angle 1 ; b) force has a fixed line of action

\section{STABILITY OF COMPRESSED RODS WITH VARIABLE RIGIDITY}

Since it is not possible to solve equation (1) analytically, we can propose an approximate approach that simplifies the task. It is obvious that continuous change of cross section dimensions and other rod parameters can be approximately simulated by a stepped dependence (Fig. 6)

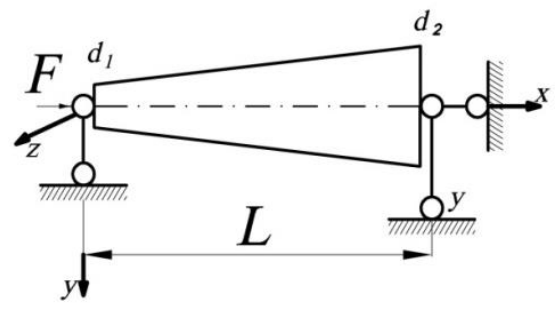

a

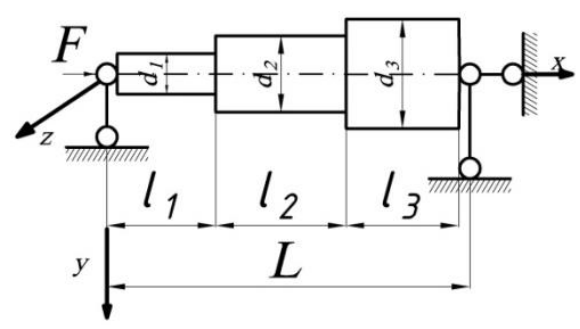

b

Fig. 6. Modeling of a truncated cone by a stepped system 
Such a replacement is very convenient because at each beam section the change in section dimensions (and other parameters) disappears and equations with variable coefficients are automatically reduced to equations with constant coefficients, which solutions exist and they are the only ones (Cauchy problems). The method that will most effectively cope with the calculation task of discretized system only remains to be used. The methods of initial parameters, displacements, finite elements, etc. can be applied. In our opinion, the numerical-analytical version of the boundary element method is most suitable here. The essence of this method comes down to elementary transformations of matrices of calculated ratios at the boundary value $x=l_{i}$ each system's element according to the scheme

$$
\begin{aligned}
\mathbf{Y}(l)= & \mathbf{A}(l) \cdot \mathbf{X}(0)+\mathbf{B}(l) \rightarrow \mathbf{A}(l) \cdot \mathbf{X}(0)-\mathbf{Y}(l)= \\
& =-\mathbf{B}(l) \rightarrow \mathbf{A}_{*}(l) \cdot \mathbf{X}_{*}(0, l)=-\mathbf{B}(l),
\end{aligned}
$$

where $\mathbf{Y}(l)$ is a state parameter vector of all rod system in the boundary sections $x=l_{i}, i=1, n$;

$\mathbf{A}(l)$ is a quasi-diagonal matrix of fundamental functions at $x=l_{i}, i=1, n$;

$\mathbf{X}(0)$ is a vector of initial parameters of all rod system;

$\mathbf{B}(l)$ is an external load vector at $x=l_{i}, i=1, n$;

$n$ is a number of elements in the system.

As a result of parameter transfer from $\mathbf{Y}(l)$ to $\mathbf{X}(0)$ is a system of linear algebraic equations obtained. If it is required to solve eigenvalue problems, then $\mathbf{B}(l)=0$ and at $\mathbf{X}_{*}(0, l) \neq 0$, the transcendental equation is obtained to search for critical forces or natural frequencies in the form of a determinant

$$
\left|\mathbf{A}_{*}\left(l, F_{k p}, \omega\right)\right|=0 \text {. }
$$

By setting the interval for $F_{\text {кр }}$ or $\omega$, you can always find your own values. Matrix $A_{*}\left(l, F_{k p}, \omega\right)$ has many remarkable properties:

1. A strong discharged matrix doesn't lead to a significant accumulation of rounding errors from arithmetic operations;

2. It is certainly scaled, that is, its elements smoothly decrease in size from left to right along the secondary diagonal. This property causes the high stability of numerical operations when solving the system of equations (2) or when calculating the determinant;

3. When $x=0$, it forms the identity matrix;

4. In problems of stability and dynamics, it doesn't contain breaking points of the 2nd kind;

5. It is formed without matrix operations of addition, multiplication and inversion. Quasidiagonalization operation is only used. 
All these advantages allow us to have the simplest algorithm for solving various boundary problems, which is characterized by high accuracy results. Let us present the BEM algorithm using the examples of the truncated cone stability problems reviewed in the works. The stability equation for the discretized scheme in Fig. 6, b and the $i$-th segment will take the form:

$$
E I_{i} \frac{d^{4} \vartheta(x)}{d x^{4}}+F \frac{d^{2} \vartheta(x)}{d x^{2}}=0 .
$$

The matrix of fundamental orthonormal functions for this equation is known, and has the form:

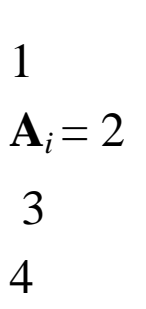

\begin{tabular}{|l|l|l|l|}
1 & 2 & 3 & 4 \\
\hline 1 & $A_{12}$ & $-A_{13} / E I_{i}$ & $-A_{14} / E I_{i}$ \\
\hline & $A_{22}$ & $-A_{12} / E I_{i}$ & $-A_{13} / E I_{i}$ \\
\hline & $-A_{32} \cdot E I_{i}$ & $A_{22}$ & $A_{12}$ \\
\hline & & & 1 \\
\hline
\end{tabular}

where

$$
\begin{gathered}
A_{12}=\frac{\sin \left(t_{i} x\right)}{t_{i}} ; A_{13}=\frac{1-\cos \left(t_{i} x\right)}{t_{i}^{2}} ; A_{14}=\frac{t_{i} x-\sin \left(t_{i} x\right)}{t_{i}^{3}} ; A_{22}=\cos \left(t_{i} x\right) ; \\
A_{32}=\sin \left(t_{i} x\right) ; t_{i}=\sqrt{F / E I_{i}}
\end{gathered}
$$

Rigidity parameters entered into matrix $\mathbf{A}_{i}$ for simpler fulfillment of the conditions of connection plots in the internal points of the beam. Values $E I_{i}$ are most easily calculated in the middle of each plot. The cross section of the cone is a circle, and the diameter varies according to the law (Fig. 1, a):

$$
d(x)=d_{1}\left(a+b x^{k}\right),
$$

where $a, b$ are coefficients;

$k$ is exponent.

Matrix $A_{*}(l, \mathrm{~F})$ of equation (3) is formed in the following way. Let $n=3$ (Fig. 1. b). The matrices of initial and final parameters of the discretized beam are compiled. They take into account the boundary conditions of the bearing and the conditions for the continuity of the parameters of bending at the internal points.

From matrix $\mathbf{X}_{*}$ it follows that in matrix $\mathbf{A}_{*}$ you need to reset 1 and 3 columns. Independent matrix $\mathrm{Y}$ parameters are carried into place of zero parameters of matrix $\mathbf{X}_{*}$. Dependent matrix $\mathrm{Y}$ parameters are transferred according to the equations of their connection. As a result, matrix $\mathbf{A}_{*}$ is supplemented with compensating elements. The beam stability matrix will look like: 


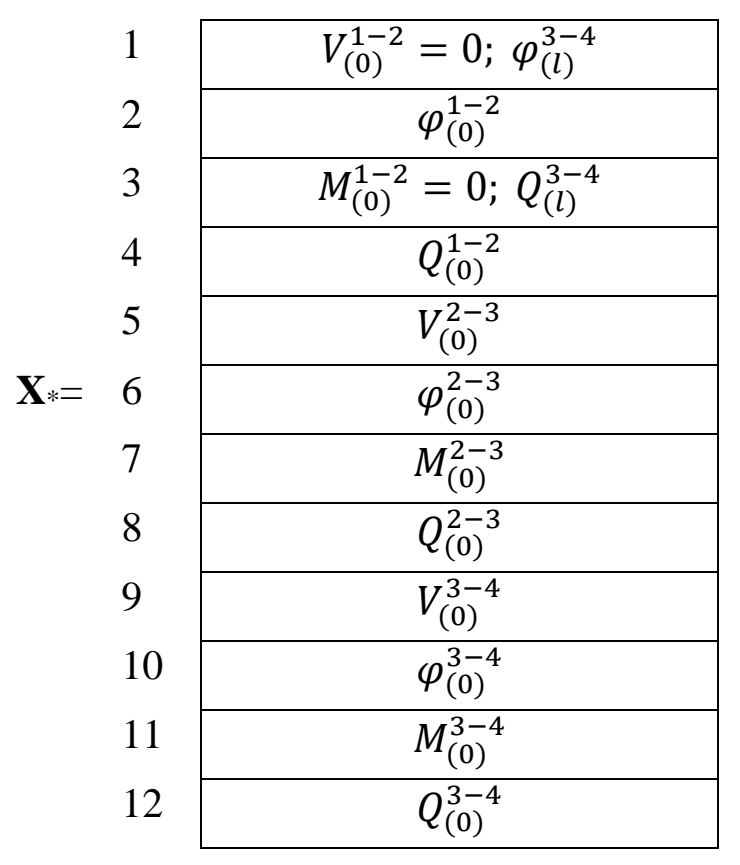

\begin{tabular}{|c|c|}
\hline 1 & $V_{(l)}^{1-2}=V_{(0)}^{2-3}$ \\
\hline 2 & $\varphi_{(l)}^{1-2}=\varphi_{(0)}^{2-3}$ \\
\hline 3 & $M_{(l)}^{1-2}=M_{(0)}^{2-3}$ \\
\hline 4 & $Q_{(l)}^{1-2}=Q_{(0)}^{2-3}$ \\
\hline 5 & $V_{(l)}^{2-3}=V_{(0)}^{3-4}$ \\
\hline $\mathbf{Y}=6$ & $\varphi_{(l)}^{2-3}=\varphi_{(0)}^{3-4}$ \\
\hline 7 & $M_{(l)}^{2-3}=M_{(0)}^{3-4}$ \\
\hline 8 & $Q_{(l)}^{2-3}=Q_{(0)}^{3-4}$ \\
\hline 9 & $V_{(l)}^{3-4}=0$ \\
\hline 10 & $\varphi_{(l)}^{3-4}$ \\
\hline 11 & $M_{(l)}^{3-4}=0$ \\
\hline 12 & $Q_{(l)}^{3-4}$ \\
\hline
\end{tabular}

\begin{tabular}{|c|c|c|c|c|c|c|c|c|c|c|c|c|}
\hline & 1 & 2 & 3 & 4 & 5 & 6 & 7 & 8 & 9 & 10 & 11 & 12 \\
\hline 1 & & $\mathrm{~A}_{12}$ & & $-\mathrm{A}_{14} / \mathrm{EI}_{1}$ & -1 & & & & & & & \\
\hline 2 & & $\mathrm{~A}_{22}$ & & $-\mathrm{A}_{13} / \mathrm{EI}_{1}$ & & -1 & & & & & & \\
\hline 3 & & $-\mathrm{A}_{32} \mathrm{EI}_{1}$ & & $\mathrm{~A}_{12}$ & & & -1 & & & & & \\
\hline 4 & & & & 1 & & & & -1 & & & & \\
\hline 5 & & & & & 1 & $\mathrm{~A}_{12}$ & $-\mathrm{A}_{12} / \mathrm{EI}_{2}$ & $-\mathrm{A}_{14} / \mathrm{EI}_{2}$ & -1 & & & \\
\hline 6 & & & & & & $\mathrm{~A}_{22}$ & $-\mathrm{A}_{12} / \mathrm{EI}_{2}$ & $-\mathrm{A}_{13} / \mathrm{EI}_{2}$ & & -1 & & \\
\hline $\mathrm{A}_{*}=$ & & & & & & $-\mathrm{A}_{32} \mathrm{EI}_{2}$ & $A_{22}$ & $A_{22}$ & & & -1 & \\
\hline 8 & & & & & & & & 1 & & & & -1 \\
\hline 9 & & & & & & & & & 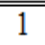 & $\overline{\mathrm{A}_{12}}$ & $-\mathrm{CA}_{13} / \mathrm{EI}_{3}$ & $-\mathrm{A}_{14} / \mathrm{EI}_{3}$ \\
\hline 10 & -1 & & & & & & & & & $A_{22}$ & $-\mathrm{A}_{12} / \mathrm{EI}_{3}$ & $-\mathrm{A}_{13} / \mathrm{EI}_{3}$ \\
\hline 11 & & & & & & & & & & $-\mathrm{A}_{32} \mathrm{EI}_{3}$ & $\mathrm{~A}_{22}$ & $\mathrm{~A}_{12}$ \\
\hline 12 & & & -1 & & & & & & & & & 1 \\
\hline
\end{tabular}

Matrix equations (20) are similarly formed for beams with other support conditions. From equation (20) by the search method you can determine the critical forces that are provided in the form:

$$
F_{\text {кр }}=\frac{\lambda^{2} E I_{\min }}{l^{2}}=\frac{\pi^{2} E I_{\min }}{(\mu l)^{2}}
$$

where $\lambda$ is a dimensionless critical force parameter;

$\mu$ is an effective length factor.

There is dependence between $\lambda$ and $\mu$.

$$
\lambda \mu=\pi
$$


The practice of solving problems with variable coefficients shows that the results are almost accurate even with the number of plots $n \geq 30$. For the problems of works matrix $\mathbf{A} *$ was formed automatically according to the program in MATLAB environment with $n=50$. Table 1 presents parameters $\lambda$ for the first three critical forces of various cone-shaped beams with $a=1$; $b=0,01 ; k=1 ; L=1$.

Table 1

The first three parameters of critical forces

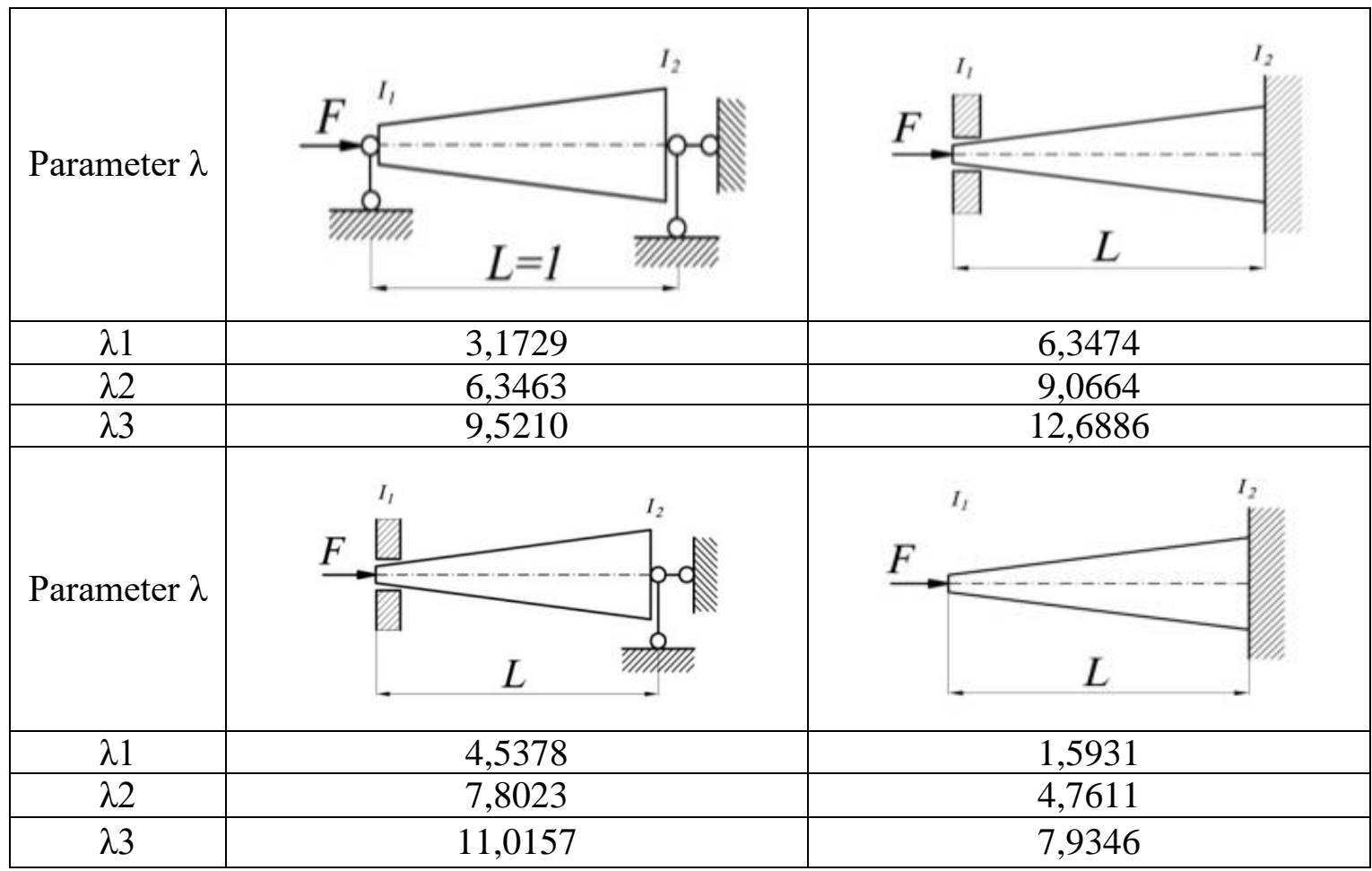

The data in Table 1 can be compared with the results of work. Using the Green function allowed us to obtain an accurate result for $\lambda 1$ with hinged support

$$
\lambda 1=3,17
$$

It can be seen that the BEM results and works coincide. Using the integral equations, the approximate value $\lambda 1=3.11$ was obtained in the work. Although this result is little different from the accurate result, it is unreliable. The value of $\lambda 1$ for a cone-shaped beam must be greater than $\pi$. Table 2 presents parameter values $\lambda 1$ depending on the diameter ratio of the coneshaped beams with $a=1 ; L=1 ; k=1$.

Table 2 shows that with a smooth change in the transverse dimensions of the rod it is possible to significantly increase the critical forces of such structures as columns, chimneys, various supports, TV and radio towers, towers. 
Parameters $\lambda 1$ when changing the diameter ratios of cross section

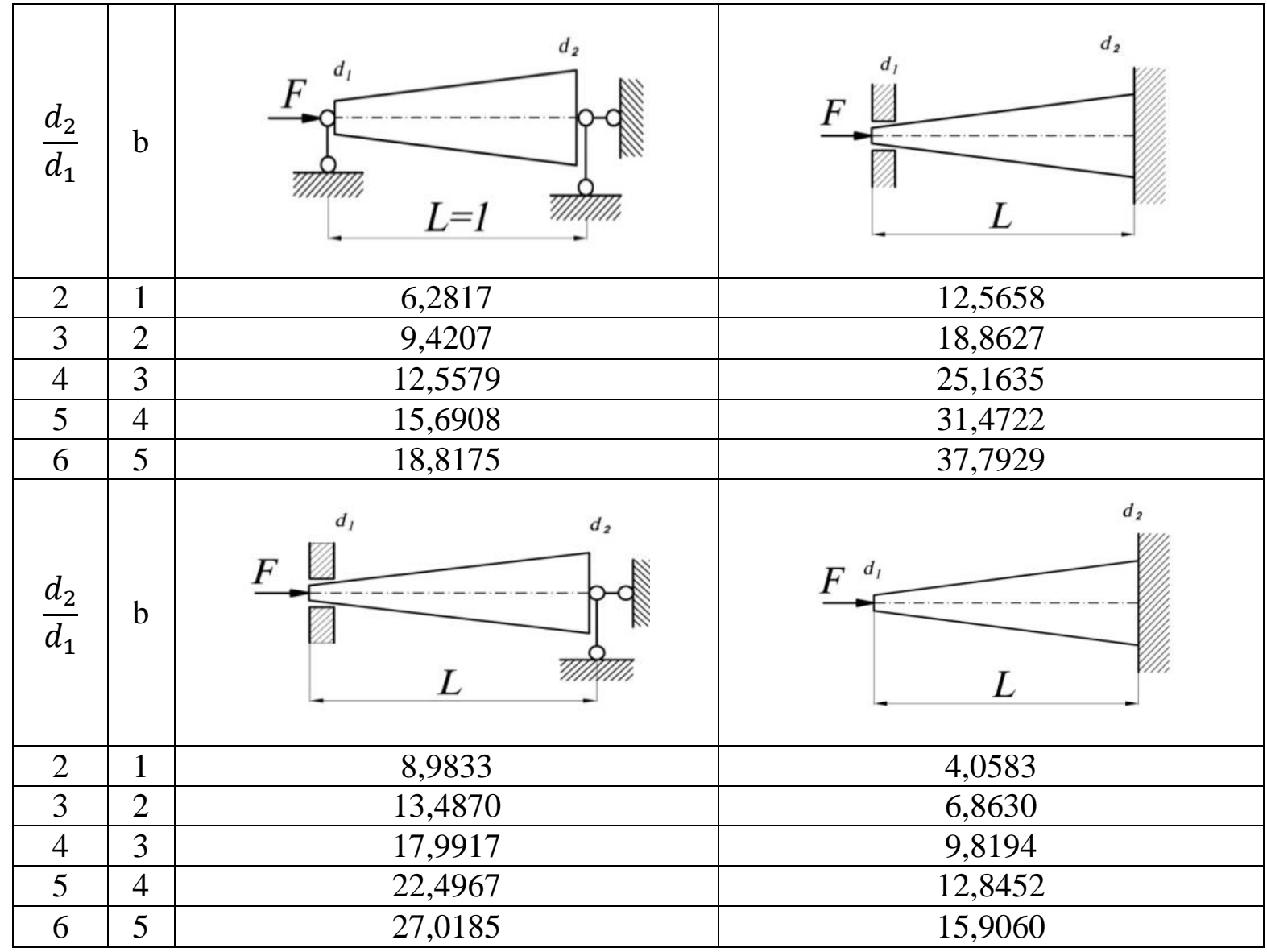

\section{CONCLUSIONS}

From Fig. 6 it follows that frame behavior significantly differs from behavior of continuous beam, where all bars experience the effect of compression force. It is significant that in elastic system the possibility of losing reliability in the form of flatter or divergence significantly depends on the length of cantilever portions. So, with a cantilever length of $l$ taken as 1 meter in the given problems, it would be possible to find neither flatter nor divergence of the structures. Also the work conclusion stating that complex structures loaded with non-conservative compressible forces have a spectrum of intermittent critical forces is approved. Therefore, non-conservative forces can cause Euler buckling mode, whose critical force is much less compared to the non-conservative critical force. In this respect, non-conservative forces in problem of stability of complicated designs are as dangerous as conservative forces.

The analysis of the presented material shows that the method of calculating the beam stability with distributed parameters, based on BEM, allows you to solve effectively, accurately and reliably the complex problems, which don't have an analytical solution. In particular, for cone-shaped (also pyramidshaped) beams, it is not necessary to form a rather cumbersome Green function 
or to solve the integral equations. In BEM it is sufficient to use only the system of fundamental orthonormal functions of the corresponding differential equation with constant coefficients. An additional advantage is the minimum requirements for variable coefficients of the differential equation. They can have breaks of the 1-st kind, break points, and an arbitraty set of continuous functions, which significantly expands the range of the solvable problems not only in the stability theory, but also in other sciences

\section{SUMMARY}

An algorithm for using the numerical-analytical version of the boundary element method to solve the stability problems of non-conservative core systems is presented. Such elements are a part of the crane support system. The aim of the study is to study the behavior of complex mechanical systems loaded with non-conservative compression forces. Similar problems arise in heavily loaded structures, and their behavior is of great scientific and practical importance. The calculation of the critical force is made in MATLAB.

This paper also discusses the problems of stability of compressed rods with a continuous change in cross-sectional dimensions in different directions. Such constructions include columns, various supports, towers, details of cranes, machines and mechanisms, various shafts and axles. It is shown that these problems are reduced to boundary value problems for ordinary differential equations with variable coefficients. To apply the boundary element method, rods with variable stiffness are divided into sections with constant stiffness, and then the matrices of the basic functions of differential equations with constant coefficients are used.

\section{REFERENCES}

1. Dashhenko A. F. Chislenno-analiticheskij metod granichnyh jelementov [Numerical-analytical method of boundary elements]. Odessa: VMV, 2010. T. 1.415 s. T. 2. $510 \mathrm{~s}$.

2. Orobej V. F. Metod granichnyh jelementov v zadachah ustojchivosti ploskoj formy izgiba balok prjamougol'nogo sechenija [Method of boundary element in problems of stability of plane bending beams of rectangular cross section]. Zbirnik naukovih prac Odeskoi deržavnoi akademii tehničnogo regulûvannâ ta âkostì. Odesa, 2015. № 2 (7). S. 47-54.

3. Orobej V. F. Metod granichnyh jelementov $\mathrm{v}$ zadachah rascheta mashinostroitel'nyh konstrukcij [The method of boundary elements in the problems of calculating engineering structures]. Odessa: "Aprel”, 2016. $761 \mathrm{~s}$. 
Information about the authors:

Orobey V. F.,

Doctor of Technical Sciences, Professor,

Professor at the Department of Dynamics, Machine Strength and Material Resistance,

Odessa National Polytechnic University 1, Shevchenko ave., Odessa, 65044, Ukraine ORCID ID: orcid.org/0000-0002-2001-2274

Nemchuk O. O., $\mathrm{PhD}$, Associate Professor, Vice Rector of Science, Corresponding Member of Transport Academy of Ukraine, Full Member of Lifting Transport Academy of Science of Ukraine, Odessa National Maritime University 34, Mechnikov str., Odessa, 65029, Ukraine ORCID ID: orcid.org/0000-0001-5633-8930

Lymarenko O. M., $\mathrm{PhD}$, Associate Professor, Head of the Department of Dynamics, Machine Strength and Material Resistance, Odessa National Polytechnic University 1, Shevchenko ave., Odessa, 65044, Ukraine ORCID ID: orcid.org/0000-0002-3607-5253 